\title{
Первый клинический опыт комбинированного лечения больных с дефектом межпредсердной перегородки и фибрилляцией предсердий с применением двухэтапного подхода
}

\author{
Ковальчук А. О., Кравченко Т. В., Эстрин С. И., Антонюк С. О., Акобиров Е. С., \\ Чижикова Е.В.
}

ГУ «Институт общей и неотложной хирургии имени В.Т. Зайцева НАМН» (Харьков)

\begin{abstract}
Наличие дефекта межпредсердной перегородки (ДМПП) патофизиологически ассоциировано с развитием фибрилляции предсердий (ФП), что требует комбинированного подхода к лечению сочетания обеих
\end{abstract} патологий.

Цель работы - изучить на небольшом клиническом материале эффективность лечения ФП методом катетерной радиочастотной абляции (РЧА), выполненной перед хирургической коррекцией вторичного ДМПП.

Материалы и методы. В 2015-2017 гг. прооперированы 5 взрослых пациентов с вторичным ДМПП в сочетании с медикаментозно рефрактерной ФП. Перед закрытием ДМПП во всех случаях первым этапом производилась чрезкожная катетерная РЧА в левом предсердии (ЛП), катетер в полость ЛП вводился через дефект в перегородке. У всех пациентов выполнена циркулярная электрическая изоляция устьев легочных вен и произведены дополнительные повреждения в ЛП. В сроки от $1(n=2)$ до $3(n=3)$ мес. после катетерной РЧА всем больным вторым этапом выполнена по показаниям хирургическая пластика ДМПП заплатой из аутоперикарда с использованием искусственного кровообращения.

Результаты и обсуждение. В результате первичной РЧА в ЛП ФП успешно устранена во всех случаях. После вмешательства все больные принимали амиодарон 200 мг/сут. У трех пациентов препарат был отменен через 1 мес., двое продолжали его принимать. У этих двух пациентов ввиду изменений миокарда предсердий считали сохранение стабильного синусового ритма без приема амиодарона бесперспективным, по истечении 1 мес. после РЧА им выполнена оперативная пластика ДМПП. Трем пациентам через 3 мес. выполнено повторное катетерное вмешательство, во время которого нанесены дополнительные аппликации в участках патологической активности. Эпизодов рецидива ФП между двумя этапами лечения не отмечено ни в одном случае. Вторым этапом у пациентов выполнена успешная хирургическая коррекция ДМПП. В сроки наблюдения от 3 до 18 мес. после операции у всех пациентов сохранялся синусовый ритм, из них двое продолжают принимать амиодарон.

Выводы. При сочетании вторичного ДМПП с ФП альтернативой сочетанной операции может быть устранение ФП методом катетерной РЧА с последующей оперативной пластикой ДМПП.

Ключевые слова: дефект межпредсердной перегородки, фибрилляция предсердий, хирургическое лечение, радиочастотная абляция.

Фибрилляция предсердий (ФП) достаточно часто ассоциирована с врожденной аномалией - вторичным дефектом межпредсердной перегородки (ДМПП). К сожалению, успешная коррекция данного порока не гарантирует полного отсутствия рецидива ФП в послеоперационном периоде и сама по себе редко способствует эффективному контролю за нормальным сердечным ритмом даже на фоне антиаритмической медикаментозной профилактики [4, 9]. Данное обстоятельство обусловливает необходимость в комбинированном подходе к лечению пациентов с ДМПП и ФП в анамнезе. В настоящее время в мировой клинической практике нет единого согласованного мнения в вопросах выбора оптимального метода и сроков лечения
ФП у пациентов с ДМПП. Ряд сообщений в литературе показывают техническую возможность выполнения чрескожной катетерной радиочастотной абляции (РЧА) после как хирургической, так и катетерной коррекции ДМПП [2, 12]. В других публикациях авторы отстаивают вариант торакоскопической абляции после закрытия ДМПП [10], в то время как современные рекомендации по лечению обеих патологий обязывают рассматривать возможность выполнения процедуры Maze во всех случаях хирургической коррекции ДМПП с наличием ФП в анамнезе [6, 8]. Чрескожная катетерная РЧА,как метод лечения рефрактерной к медикаментозной терапии ФП является малоинвазивной методикой и хорошо зарекомендовала себя в лече- 
нии пациентов с изолированной формой аритмии [11]. Эффективность же катетерной РЧА при сочетании ФП с ДМПП, вероятно, зависит от степени морфологических изменений в миокарде обоих предсердий и их необратимости, что связано, в свою очередь, с длительной гемодинамической перегрузкой последних из-за существования дефекта на протяжении определенного промежутка времени. В данной статье на клиническом материале описывается и практически обосновывается целесообразность этапного подхода к лечению сочетанных ДМПП и ФП, при которых катетерная РЧА выполняется в первую очередь перед хирургическом закрытием дефекта перегородки.

Цель - изучить на небольшом клиническом материале эффективность лечения ФП методом катетерной РЧА, Выполненной перед хирургической коррекцией вторичного ДМПП.

Материалы и методы. В 2015-2017 гг. нами последовательно прооперированы 5 пациентов в возрасте от 41 до 67 лет с диагностированным вторичным ДМПП в сочетании с медикаментозно рефрактерной ФП. Клинические и эхокардиографические характеристики пациентов приведены в табл. 1. Средняя фракция выброса (ФВ) левого желудочка, средний диаметр левого предсердия (ЛП), средний диаметр ДМПП и среднее систолическое давление в легочной артерии (ЛА) составляли $66 \%$, 6,0 см, 2,6 см и 48 ммНg соответственно. Пациенты были всесторонне обследованы: выполнены общеклинические лабораторные обследования, исключена дисфункция щитовидной железы, выполнены электрокардиография (ЭКГ), трансторакальная и чреспищеводная эхокардиография (ЭхоКГ), холтеровское мониторирование (ХМ) ЭКГ, коронарография (КГ). По результатам КГ, коронарное русло у всех обследованных не имело значимых поражений, что свидетельствовало о преимущественно неишемическом генезе аритмии. У 4 пациентов была персистирующая форма ФП, у 1 пароксизмальная. У всех больных антиаритмические препараты (ААП), включая амиодарон, были неэффективны. Размеры, форма ДМПП, его расположение в перегородке, а также величина левоправого сброса определялись при помощи ЭхоКГ с допплеровским картированием, согласно его результатам все пациенты подлежали хирургической коррекции порока вследствие анатомических особенностей дефекта. Перед закрытием ДМПП во всех случаях первым этапом производилась чрескожная катетерная РЧА в ЛП, при этом катетер в полость ЛП вводился через дефект в перегородке. Объем РЧА в ЛП определяли путем оценки следующих показателей: форма ФП, объем ЛП, наличие аномальной электрической активности (фрагментированные, низкоамплитудные электрограммы, участки фиброза). У всех пациентов выполнена циркулярная электрическая изоляция устьев легочных вен (ЛВ) и произведены дополни-
Таблица 1

Клинико-морфологические данные пациентов

\begin{tabular}{lccccc} 
& № 1 & № 2 & № 3 & № 4 & № 5 \\
\hline Возраст (лет) & 64 & 57 & 67 & 41 & 62 \\
\hline Пол (м/ж) & ж & ж & ж & М & ж \\
\hline Анамнез ФП (мес.) & 6 & 12 & 24 & 11 & 3 \\
\hline $\begin{array}{l}\text { Тип ФП (персист./ } \\
\text { парокс.) }\end{array}$ & $\begin{array}{l}\text { пер- } \\
\text { сист. }\end{array}$ & $\begin{array}{c}\text { пер- } \\
\text { сист. }\end{array}$ & $\begin{array}{c}\text { пер- } \\
\text { сист. }\end{array}$ & $\begin{array}{c}\text { пер- } \\
\text { сист. }\end{array}$ & $\begin{array}{c}\text { па- } \\
\text { рокс. }\end{array}$ \\
\hline Диаметр ДМПП (см) & 3,2 & 1,9 & 2,6 & 2,1 & 3,0 \\
\hline Диаметр ЛП (см) & 5,5 & 5,9 & 7,6 & 4,8 & 6,2 \\
\hline Диаметр ПП (см) & 5,2 & 5,5 & 5,1 & 5,0 & 5,7 \\
\hline $\begin{array}{l}\text { Систолическое дав- } \\
\text { ление } \\
\text { В ЛА (ммНу) }\end{array}$ & 47 & 50 & 48 & 40 & 54 \\
\hline $\begin{array}{l}\text { Трикуспидальная ре- } \\
\text { гургитация (степень) }\end{array}$ & II & III & II & II & III \\
\hline ФВ (\%) & 64 & 59 & 70 & 67 & 70
\end{tabular}

тельные точечные и линейные повреждения в ЛП. У 1 больного дополнительно выполнена РЧА правопредсердного трепетания. Конечными точками процедуры были: электрическая изоляция всех ЛВ, блокада проведения через линию повреждения, снижение локальной амплитуды электрограммы в месте воздействия на 90\%, наличие синусового ритма в конце процедуры. В течение 1 месяца все пациенты принимали амиодарон в дозе 200 мг/сут. В дальнейшем препарат был отменен у трех больных, и им через 3 месяца после первой процедуры для оценки ее результатов произведено повторное катетерное вмешательство. Двум пациентам отмену амиодарона и повторную катетерную процедуру посчитали нецелесообразной из-за выраженных изменений в миокарде предсердий. В сроки от $1(n=2)$ до $3(n=3)$ месяцев после первичной катетерной РЧА всем больным выполнена хирургическая коррекция дефекта с искусственным кровообращением.

Результаты и обсуждение. Во время 1-й процедуры РЧА электрическая изоляция устьев ЛВ с т. н. двунаправленной блокадой успешно достигнута во всех случаях. Дополнительные РЧА в зонах наличия фрагментированной активности (перегородка, крыша ЛП) выполнена всем пациентам, у 1 выполнялись линейные повреждения в ЛП (по крыше, через передний перешеек) с достижением блокады проведения через линию. В послеоперационном периоде все больные принимали амиодарон 200 мг/сут. У трех пациентов препарат был отменен через 1 месяц, двое продолжали принимать. У этих двоих пациентов из-за выраженных изменений миокарда предсердий (о чем свидетельствовало наличие аномальной электрической активности и зон фиброза) считали наличие стабильного синусового ритма без приема ААП бесперспективным. Поэтому по истечении 1 месяца после РЧА им выпол- 


\section{Таблица 2}

Послеоперационные результаты

\begin{tabular}{|c|c|c|c|c|c|}
\hline & № 1 & № 2 & № 3 & № 4 & № 5 \\
\hline Продолжитель- & & & & & \\
\hline $\begin{array}{l}\text { ность приема } \\
\text { амиодарона после } \\
\text { РчА (мес.) }\end{array}$ & 1 & $\begin{array}{l}\text { посто- } \\
\text { янно }\end{array}$ & 1 & 1 & $\begin{array}{c}\text { посто- } \\
\text { янно }\end{array}$ \\
\hline $\begin{array}{l}\text { Время между РЧА } \\
\text { и операцией (мес.) }\end{array}$ & 3 & 1 & 3 & 3 & 1 \\
\hline $\begin{array}{l}\text { Контрольное ис- } \\
\text { следование с РЧА } \\
(+/-)\end{array}$ & + & - & + & + & - \\
\hline $\begin{array}{l}\text { Рецидивы ФП } \\
\text { между РЧА и опе- } \\
\text { рацией (+/-) }\end{array}$ & - & - & - & - & - \\
\hline $\begin{array}{l}\text { Сроки наблюдения } \\
\text { (мес.) }\end{array}$ & 18 & 12 & 17 & 10 & 3 \\
\hline $\begin{array}{l}\text { Послеопера- } \\
\text { ционный ЭКГ- } \\
\text { мониторинг }\end{array}$ & $\begin{array}{l}\text { сину- } \\
\text { совый } \\
\text { ритм }\end{array}$ & $\begin{array}{l}\text { сину- } \\
\text { совый } \\
\text { ритм }\end{array}$ & $\begin{array}{l}\text { сину- } \\
\text { совый } \\
\text { ритм }\end{array}$ & $\begin{array}{l}\text { сину- } \\
\text { совый } \\
\text { ритм }\end{array}$ & $\begin{array}{l}\text { сину- } \\
\text { совый } \\
\text { ритм }\end{array}$ \\
\hline
\end{tabular}

нена оперативная коррекция ДМПП. Трем пациентам через 3 месяца выполнено повторное катетерное вмешательство, во время которого при ревизии ЛВ выявлено локальное восстановление проведения из вены у 1 больного, выполнена реизоляция вены, производилась ревизия выполненных ранее абляционных линий, которые были состоятельными. Во время повторного вмешательства у 1 пациентки выявлена «новая» тахикардия: re-entry вокруг дефекта перегородки, тахикардия устранена путем выполнения линии РЧА от правой верхней ЛВ до дефекта. Осложнений во время и после процедур (первичных и контрольных) не было. В конце срока наблюдения производилась оценка клинического статуса, регистрировалась ЭКГ, ХМ ЭКГ, ЭхоКГ, по результатам которых у всех больных удерживался синусовый ритм. Вторым этапом пациентам в условиях искусственного кровообращения выполнено хирургическое закрытие ДМПП заплатой из аутоперикарда, которое в 2 случаях было дополнено шовной аннулопластикой трикуспидального клапана. Послеоперационная ЭхоКГ показала отсутствие у всех прооперированных лево-правого межпредсердного сброса крови, что свидетельствует об успешности коррекции порока. В сроки наблюдения от 3 до 18 месяцев у всех пациентов сохраняется синусовый ритм (из них 2 принимают амиодарон). Результаты лечения пациентов представлены в табл. 2.

В течение всего времени наблюдения у всех прооперированных регистрировался синусовый ритм, что свидетельствует о сопоставимой эффективности метода РЧА в лечении ФП в популяции пациентов с ДМПП и интактной перегородкой. Другими очевидными преимуществами данного подхода является минимизация объема хирургического вмешательства, который сводится исключительно к пластике дефекта без хирургической коррекции ФП, а также относительная техническая простота выполнения РЧА при некорригированном ДМПП, поскольку отсутствует необходимость в специальном инструментарии для транссептальной пункции. В сравнении с примененным нами подходом вариант сочетанной операции, т. е. процедура Maze в дополнение к хирургическому закрытию ДМПП, имеет недостатки в виде повышенной хирургической сложности, большей травматичности и связанных с этим специфических хирургических осложнений $[1,5]$. Торакоскопическая абляция после коррекции ДМПП требует специального оборудования и определенных навыков оперирующей бригады, что препятствует широкому клиническому внедрению данного метода $[3,7]$. Вариант выполнения чрескожной катетерной РЧА после закрытия ДМПП практически возможен, однако представляет значительные технические трудности ввиду необходимости транссептальной пункции через ограниченный участок перегородки вдоль задне-нижнего края заплаты (или окклюдера), что может быть успешным в большинстве случаев только под интракардиальным эхоскопическим контролем [7, 12]. Таким образом, наряду с вышеперечисленными вариантами, предложенный нами этапный подход, при котором чрескожная катетерная РЧА с устранением ФП выполняется до хирургической коррекции ДМПП, является приемлемой альтернативой в лечении пациентов с сочетанием обеих патологий.

\section{Выводы}

1. При сочетании вторичного ДМПП с ФП альтернативой сочетанной операции может быть устранение ФП методом катетерной РЧА с последующей пластикой дефекта перегородки.

2. Перед выполнением хирургического пособия целесообразно выполнить повторную катетерную процедуру для оценки результатов первичной и возможной дополнительной абляции патологических очагов.

3. Интервал в 3 месяца между РЧА и оперативной пластикой ДМПП оптимален для адекватного пост-абляционного мониторинга сердечного ритма, однако в случаях высокой вероятности рецидива ФП может быть сокращен до 1 месяца.

\section{Литература}

1. Katherine Kearney, Rowan Stephenson, Tristan D. Yan. A systematic review of surgical ablation versus catheter ablation for atrial fibrillation // Annals of Cardiothoracic Surgery. - 2014. - Vol. 3 (1). - P. 15-29.

2. Safety and feasibility of transseptal puncture for atrial fibrillation in patients with atrial septal defect closure devices / Xuping Li, M.D., Eric Wissner, F.H.R.S., [...], Feifan Ouyang, M.D. // Heart Rhythm. - 2013, November 18. doi: https//doi.org/10.1016/j.hrthm.2013.11.011. 
3. Thoracoscopic surgical ablation versus catheter ablation for atrial fibrillation / Kevin Phan, Steven Phan, Aravinda Thiagalingam et al. // European Journal of CardioThoracic Surgery. - 2016. - Vol. 49 (4). - P. 1044-1051.

4. Sing-Chien Yap. Atrial fibrillation and stroke after atrial septal defect closure. Is earlier closure warranted? // Heart. - 2015. - 101 (9). - P. 661-662.

5. Linda Henry, Niv Ad. Performance of the Cox Maze procedure - a large surgical ablation center's experience // Annals of Cardiothoracic Surgery. - 2014. - Vol. 3 (1). P. 62-69.

6. 2016 ESC Guidelines for the management of atrial fibrillation developed in collaboration with EACTS / Paulus Kirchhof, Stefano Benussi, [...], Panagiotis Vardas, ESC Scientific Document Group // European Heart Journal 2016. - Vol. 37 (38). - P. 2893-2962.

7. Percutaneous radiofrequency catheter ablation for atrial fibrillation prior to atrial septal defect closure / Mark A. Crandall, M.D., Emile G. Daoud, M.D., Curt J. Daniels, M.D., Steven J. Kalbfleisch, M.D. // Journal of Cardiovascular Electrophysiology. - 2012. Vol. 23. - P. 102-104.

8. ACC/AHA 2008 Guidelines for the management of adults with congenital heart disease: a report of the American College of Cardiology/American Heart Association
Task Force on Practice Guidelines (writing committee to develop guidelines on the management of adults with congenital heart disease) / Warnes C. A., Williams R. G., Bashore T. M., [...], Webb G. D. // Circulation. - 2008. Vol. 118. - P. 714-833.

9. Atrial flutter/fibrillation in patients receiving transcatheter closure of atrial septal defect / Shuenn-Nan Chiu, MeiHwan Wu, [...], Jou-Kou Wang // Journal of the Formosan Medical Association. - 2017. - Vol. 116 (7). - P. 522-528.

10. Totally thoracoscopic ablation for treatment of atrial fibrillation after atrial septal defect device closure / Young Su Kim, M.D., Dong Seop Jeong, M.D., [...],Young Keun On, M.D. // The Korean Journal of Thoracic and Cardiovascular Surgery. - 2014. - Vol. 47 (3). - P. 280282.

11. Long-term outcomes after ablation of persistent atrial fibrillation: an observational study over 6 years / Gareth J. Wynn, Moutaz El-Kadri, Iram Haq, [...], Dhiraj Gupta // Open Heart. - 2016. - Vol. 3 (2). - P. 394.

12. Stefano Bartoletti, M.D., Pasquale Santangeli, M.D., Andrea Natale, M.D. Catheter ablation of atrial fibrillation in patients with hardware in the heart - septal closure devices, mechanical valves and more // Journal of Atrial Fibrillation. - 2013. - Vol. 6 (1). -P. 851.

\section{First clinical experience of combined treatment of patients with atrial septal defect and atrial fibrillation using a two-staged approach}

Kovalchuk A. O., Kravchenko T. V., Estrin S. I., Antonyuk S. O., Akobirov Y. S., Chizhikova O. V.

SI "Zaitsev V. T. Institute of General and Urgent Surgery of National Academy of Medical Sciences of Ukraine» (Kharkiv)

Atrial septal defect (ASD) is pathophysiologically associated with atrial fibrillation (AF) development, so this requires an integrated approach in treating patients with these both pathologies.

Aim of work: on the basis of some clinical cases to study the efficiency of catheter radiofrequency ablation (RFA), performed before the surgical ASD closure, in treating AF.

Materials and methods. In 2015-2017 5 consecutive adult patients having secondary ASD combined with recurrent medically refractory AF have been treated. Prior to ASD closure each patient underwent catheter RFA in left atrium (LA) using a circular pulmonary vein antral isolation approach and additional lesions, while the ablating catheter was introduced into LA via septal defect. In terms from $1(n=2)$ up to $3(n=3)$ months after RFA each patient underwent surgical ASD closure with autopericardial patch by dint of artificial circulation.

Results and discussion. AF has been successfully eliminated after RFA in all cases. All patients were given amiodaronum $200 \mathrm{mg}$ /day. After 1 month it was discontinued in 3 patients wich had control catheter procedure after 3-month postablation with additional lesions in abnormal activity areas. Other 2 patients, due to the significant changes in atrial myocardium, had an uncertain prognosis as to keeping the sinus rythm witout therapy, so the surgery was provided after 1-month postablation, and amiodaronum has been held up to present. No recurrent events of AF have been registered in all cases before the surgery. Each patient underwent successful operative closure of ASD. In terms from 3 to 18 months of post-operative follow-up all patients has preserved sinus rythm.

Conclusions. In patients with both medically refractory AF and amenable to operative closure secondary ASD a staged approach with catheter RFA preceeding surgery is an acceptable alternative to combined surgical procedure.

Key words: atrial septal defect, atrial fibrillation, surgical treatment, radiofrequency ablation. 


\title{
Перший клінічний досвід комбінованого лікування хворих із дефектом міжпередсердної перегородки та фібриляцією передсердь із застосуванням двохетапного підходу
}

\author{
Ковальчук А. О., Кравченко Т. В., Естрін С. І., Антонюк С. О., Акобіров Є. С., Чижикова О. В. \\ ДУ «Інститут загальної та невідкладної хірургії імені В. Т. Зайцева НАМН» (Харків)
}

Наявність дефекту міжпередсердної перегородки (ДМПП) патофізіологічно асоційована з розвитком фібриляції передсердь (ФП), що потребує комбінованого підходу до лікування сполучення обох патологій.

Мета роботи - дослідити на обмеженому клінічному матеріалі ефективність лікування ФП методом катетерної радіочастотної абляції (РЧА), яка виконувалась перед хірургічною корекцією вторинного ДМПП.

Матеріали та методи. У 2015-2017 pр. прооперовано 5 дорослих пацієнтів із вторинним ДМПП у поєднанні з медикаментозно рефрактерною ФП. Перед закриттям ДМПП в усіх випадках першим етапом виконувалась черезшкірна катетерна РЧА в лівому передсерді (ЛП), катетер у порожнину ЛП вводився через дефект у перегородці. У всіх пацієнтів виконано циркулярну електричну ізоляцію усть легеневих вен (ЛВ) та здійснено додаткові ушкодження в ЛП. В терміни від $1(\mathrm{n}=2)$ до $3(\mathrm{n}=3)$ міс. після катетерної РЧА всім хворим другим етапом за показаннями зроблено хірургічну пластику ДМПП заплатою з аутоперикарда з використанням штучного кровообігу.

Результати та обговорення. В результаті первинної РЧА в ЛП ФП успішно усунена в усіх випадках. Після втручання всі хворі приймали аміодарон 200 мг/доб. Трьом пацієнтам препарат було скасовано через 1 міс., двоє продовжували приймати. У цих двох з огляду на зміни міокарда передсердь вважали збереження стабільного синусового ритму без прийому аміодарону безперспективним, через 1 міс. після РЧА їм виконано оперативну пластику ДМПП. У трьох пацієнтів через 3 міс. виконувалося повторне катетерне втручання, під час якого було завдано додаткових ушкоджень у ділянках патологічної активності. Епізодів рецидиву ФП між двома етапами лікування не відзначено в жодному випадку. Другим етапом пацієнтам проведено успішну хірургічну корекцію ДМПП. В терміни спостереження від 3 до 18 міс. після операції в усіх пацієнтів зберігався синусовий ритм, з них двоє продовжують приймати аміодарон.

Висновки. При сполученні вторинного ДМПП із ФП альтернативою поєднаної операції може бути усунення ФП методом катетерної РЧА з подальшою оперативною пластикою ДМПП.

Ключові слова: дефект міжпередсердної перегородки, фібриляція передсердь, хірургічне лікування, радіочастотна абляція. 